\title{
Genetically Engineered NY-ESO-1-specific T Lymphocytes
}

National Cancer Institute

\section{Source}

National Cancer Institute. Genetically Engineered NY-ESO-1-specific T Lymphocytes. NCI Thesaurus. Code C116846.

A preparation of human T-lymphocytes recognizing the tumor-associated antigen (TAA), cancer/testis antigen 1 (NY-ESO-1), with potential immunostimulating and antineoplastic activities. Genetically eng ineered NY-ESO-1-specific T-lymphocytes target tumor cells expressing the NY-ESO-1 antigen, resulting in tumor cell lysis. NY-ESO-1, an antigen found in normal testis, is overexpressed on the surface of various tumor cell types. 